\title{
Prevalence and treatment of chronic airways obstruction in adults over the age of 45
}

\author{
Deborah S Renwick, Martin J Connolly
}

\begin{abstract}
Background - Chronic airways obstruction is common in adults and the elderly. To investigate the possibility that older adults with obstructive airways disease frequently do not receive appropriate treatment, the respiratory symptoms, medication use, and pulmonary function were studied in a random sample of white adults aged over 45 living in central Manchester, UK.
\end{abstract}

Methods - A postal questionnaire survey was performed on 783 men and women aged 45 years and over selected from GP lists by random number tables. Subjects completing the questionnaire were invited to attend for pulmonary function testing and methacholine challenge (Newcastle dosimeter method).

Results - The questionnaire response rate was $92.3 \%$ ( 723 subjects). The mean age of the population was $66 \cdot 1$ years and $57 \cdot 2 \%$ were women; $29 \cdot 2 \%$ were current smokers and $37 \cdot 3 \%$ were ex-smokers. Asthma or bronchitis was reported by $30 \cdot 0 \%$. Two hundred and forty seven representative subjects attended for pulmonary function testing and spirometric evidence of chronic airways obstruction was found in $\mathbf{2 6} \cdot \mathbf{4} \%$. Respiratory symptoms were reported by $76.6 \%$ of subjects with chronic airways obstruction; $55 \cdot 0 \%$ had features which may predict potential improvement on treatment (increased non-specific bronchial responsiveness or significant bronchodilator reversibility). However, only $55 \cdot 4 \%$ of subjects with airways obstruction had received a diagnosis of asthma or chronic bronchitis and only $36.9 \%$ were using inhaled bronchodilators or steroids.

Conclusions - Chronic airways obstruction is very common in adults in this inner city population, but is frequently overlooked. Most subjects with chronic airways obstruction are not receiving appropriate treatment.

(Thorax 1996;51:164-168)

Keywords: chronic airways obstruction, inhaled bronchodilators, epidemiology.

Chronic airways obstruction is common; surveys give a prevalence in the elderly of approximately $16 \%$ (asthma plus smoking-related airways obstruction). ${ }^{12}$ However, studies often contain few elderly people. ${ }^{34}$

It was our clinical impression that many older people with chronic airways obstruction do not receive appropriate drug treatment. In a study of older adults attending day hospitals and living in local authority homes, Banerjee et al found a prevalence of reversible airways obstruction of $>40 \%$, although only $3 \%$ were using respiratory medications. ${ }^{5}$ Two surveys of elderly nursing home residents found that $10 \%$ or less were prescribed bronchodilators ${ }^{67}$; this is probably much less than the proportion with chronic airways obstruction given the estimate for the general elderly population. ${ }^{2}$ There have been no assessments of the proportion of people with chronic airways obstruction receiving appropriate drug treatment among the community dwelling elderly. We have investigated respiratory symptoms, medication use, and pulmonary function in an age stratified random population sample of adults over the age of 45 .

\section{Methods}

POPULATION SAMPLING

The study was approved by Central Manchester Health Authority ethical committee. We aimed to study a random sample of the local population aged $\geqslant 45$ years including large numbers of elderly people. Between January 1992 and February 1994 names and addresses were taken using random number tables from practice lists of 22 local general practitioners. Non-white subjects were excluded because of interracial differences in bronchial responsiveness. ${ }^{8}$ General practitioners excluded those who were confused or housebound, plus the few unsuitable for other reasons. In order to increase the numbers of older subjects only those aged $\geqslant 70$ were selected during the final months of recruitment.

Subjects were sent an explanatory letter and questionnaire concerning previous diagnoses of asthma, chronic bronchitis, and ischaemic heart disease; current medication; smoking history; and respiratory symptoms. Questions on respiratory symptoms were adapted from the MRC respiratory symptoms questionnaire. ${ }^{9}$ Non-responders were sent a repeat questionnaire, followed if necessary by an abbreviated questionnaire containing only questions about previous diagnoses and smoking habits. Half of the persistent non-responders were randomly contacted by telephone or home visit.

\section{PULMONARY FUNCTION TESTING}

Patients were excluded from the methacholine challenge if they had a history of ischaemic heart disease or were receiving current medication with $\beta$ blockers, anticholinergic med- 
ications, or oral steroids. Subjects not excluded on these grounds were invited to attend Manchester Royal Infirmary. Attendance was delayed for six weeks after respiratory tract infection or exacerbation of wheezing. Subjects were requested to refrain from caffeine for 12 hours, and to omit bronchodilators for 12 hours (inhalers), 24 hours (oral preparations), or 48 hours (sustained release preparations) before attendance.

Written informed consent was obtained from all subjects. Resting 12-lead electrocardiography (ECG) was performed, and if this showed evidence of myocardial ischaemia subjects were also excluded from methacholine challenge. Baseline pulmonary function was measured (Compact, Vitalograph, Buckingham, UK) (mean of the best six readings reproducible within $10 \%) .{ }^{1011}$ Methacholine challenge was performed by subjects with baseline forced expiratory volume in one second $\left(\mathrm{FEV}_{1}\right)$ of $\geqslant 60 \%$ predicted $^{12}$; if $\mathrm{FEV}_{1}$ was $<60 \%$ predicted $\beta$ agonist reversibility was assessed.

\section{$\beta$ AGONIST REVERSIBILITY}

$\mathrm{FEV}_{1}$ measurements were repeated 10 minutes after inhalation of $1 \mathrm{mg}$ terbutaline via a metered dose inhaler and large volume spacer (Nebuhaler, Astra Pharmaceuticals, Hertfordshire, UK). A positive result was defined as an increase in $\mathrm{FEV}_{1}$ of $\geqslant 160 \mathrm{ml}^{13}$

\section{METHACHOLINE CHALLENGE}

This was performed by the Newcastle dosimeter method. ${ }^{10114}$ Briefly, doubling doses of nebulised methacholine were inhaled at five minute intervals by the subject while seated and wearing a noseclip. $\mathrm{FEV}_{1}$ (mean of three recordings reproducible within $10 \%$ ) was measured before each subsequent dose. End points were a $20 \%$ decrease in $\mathrm{FEV}_{1}$ or administration of a maximum cumulative dose of $6.4 \mathrm{mg}$ methacholine. Results were expressed as the methacholine dose producing a $20 \%$ fall in $\mathrm{FEV}_{1}\left(\mathrm{PD}_{20}\right) .{ }^{11}$ Increased non-specific bronchial responsiveness was defined as a $\mathrm{PD}_{20}$ of $<400$ $\mu \mathrm{g}$ methacholine. ${ }^{11}$ Repeatability of methacholine challenge was assessed in 21 subjects who agreed to attend on a second occasion 3-10 days after the initial challenge.

\section{DATA ANALYSIS}

Subgroups were compared by grouped $t$ test and $\chi^{2}$ tables. Significance was defined at the $5 \%$ level.

\section{Results}

DEMOGRAPHIC DETAILS OF STUDY POPULATION AND RESPONSE RATE

Of 893 subjects contacted, 110 were ineligible (78 incorrect address, 15 dead, six non-white, 11 housebound/confused/disabled). This left 783 eligible subjects, 508 of whom returned the full questionnaire and 170 the abbreviated questionnaire. Twenty nine subjects declined
Table 1 Demographic details of study population

\begin{tabular}{lr}
\hline Mean age (years) & $66 \cdot 1$ \\
\% women & $57 \cdot 2$ \\
\% reporting asthma & $7 \cdot 3$ \\
\% reporting bronchitis & $15 \cdot 4$ \\
\% reporting asthma plus bronchitis & $7 \cdot 3$ \\
\% current smokers & $29 \cdot 2$ \\
\% ex-smokers & $37 \cdot 3$ \\
\hline
\end{tabular}

to take part. Forty five randomly selected nonresponders agreed to complete the abbreviated questionnaire; a further 12 were found to have moved away before the start of the study and were therefore not included. Thus, questionnaire information was available for 723 $(92.3 \%)$ of the 783 eligible subjects. The age and sex of all subjects was obtained from GP records. Demographic details of the study population are summarised in table 1; the age distribution of the population is shown in the figure.

Fifty three subjects reported asthma, 111 bronchitis, and a further 53 both asthma and bronchitis; overall, 217 of the $723(30.0 \%)$ reported asthma or bronchitis. This proportion was not significantly different in subjects aged less than 65 years ( 94 of 292 subjects $(32 \cdot 2 \%)$ ) or 65 years and over (123 of 431 subjects $(28 \cdot 5 \%))$. Of the 508 subjects returning the full questionnaire $15 \%$ were using inhaled medications. The prevalence of inhaler use by subjects reporting asthma or bronchitis was $46.4 \%$ $(72.0 \%$ for subjects reporting asthma, $39.9 \%$ for those reporting bronchitis).

\section{PULMONARY FUNCTION, REVERSIBILITY AND METHACHOLINE CHALLENGE}

Of the 508 subjects returning the full questionnaire, the responses of 113 excluded them from methacholine challenge (ischaemic heart disease $83 ; \quad \beta$ blockers/anticholinergics/oral steroids 48 ). The remaining 395 were invited to attend for methacholine challenge: 247 subjects actually attended $(62.5 \%$ of those invited to attend; $31.5 \%$ of the total eligible study popu-

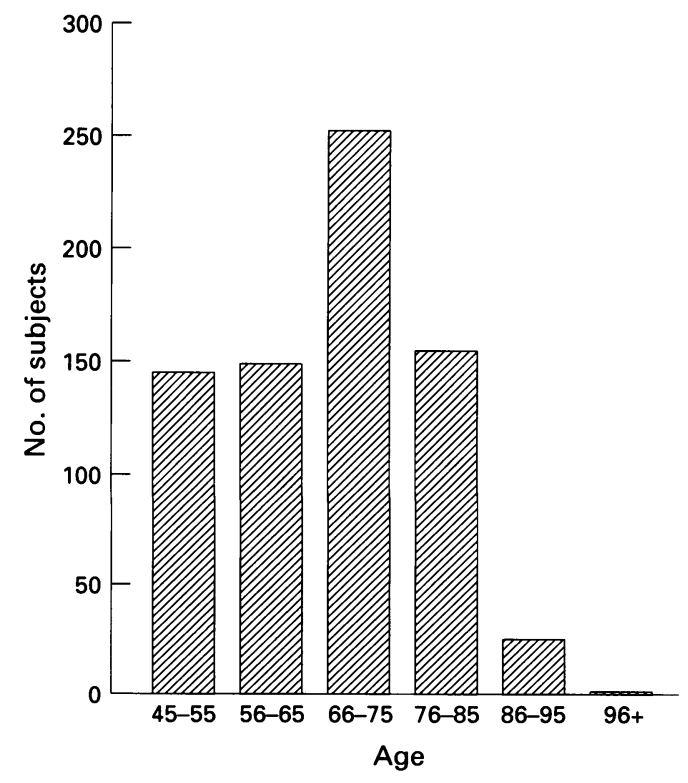

Age distribution of responders to questionnaire. 
Table 2 Mean (SD) results of spirometric tests

\begin{tabular}{|c|c|c|c|}
\hline & $\begin{array}{l}\text { All attenders } \\
(n=246)\end{array}$ & $\begin{array}{l}\text { Subjects with } \\
\text { chronic airways } \\
\text { obstruction } \\
(n=65)\end{array}$ & $\begin{array}{l}\text { Subjects without } \\
\text { chronic airways } \\
\text { obstruction } \\
(n=181)\end{array}$ \\
\hline $\begin{array}{l}\mathrm{FEV}_{1} / \mathrm{FVC} \% \\
\mathrm{FEV}_{1} \text { (\% } \\
\text { predicted) }\end{array}$ & $\begin{array}{l}69 \cdot 2(11 \cdot 6) \\
86.9(24 \cdot 5)\end{array}$ & $\begin{array}{l}54 \cdot 2(7 \cdot 7) \\
63 \cdot 6(24 \cdot 0)\end{array}$ & $\begin{array}{l}74 \cdot 6(7 \cdot 2) \\
94 \cdot 6(18 \cdot 9)\end{array}$ \\
\hline $\begin{array}{l}\text { Age (years) } \\
\% \text { women }\end{array}$ & $\begin{array}{l}64 \cdot 5(10 \cdot 8) \\
56 \cdot 7\end{array}$ & $\begin{array}{l}66 \cdot 3(10 \cdot 0) \\
53 \cdot 8\end{array}$ & $\begin{array}{l}63 \cdot 8(11 \cdot 1) \\
57 \cdot 4\end{array}$ \\
\hline
\end{tabular}

$\mathrm{FEV}_{1}=$ forced expiratory volume in one second; $\mathrm{FVC}=$ forced vital capacity

lation). The mean age of attenders was 64.5 years (range $45-86$ years); this was younger than the population as a whole $(p=0.02$, grouped $t$ test). There was no significant difference between the 247 attenders and the 783 eligible subjects in sex distribution $(56.7 \%$ women in attender group), reporting of asthma or bronchitis, reporting of respiratory symptoms, or smoking habits $33.6 \%$ of attenders were current smokers and $38.5 \%$ were exsmokers).

One subject was unable to perform reproducible measurements of baseline spirometry and thus data were available for 246 attenders (table 2). Chronic airways obstruction was defined as an $\mathrm{FEV}_{1} / \mathrm{FVC} \%$ of $<65 \%$ for subjects aged $<65$ years; for those aged $\geqslant 65$ years a predicted value and lower limit of normal for $\mathrm{FEV}_{1} / \mathrm{FVC} \%$ was calculated as described by Enright et al.$^{15}$ Using these criteria, the prevalence of chronic airways obstruction was $26.4 \%(22.9 \%$ in 118 attenders aged $<65$ years and $29 \cdot 7 \%$ in the 128 attenders aged $\left.\geqslant 65\left(\chi^{2}=1 \cdot 46, p=0 \cdot 2\right)\right)$. Airways obstruction was equally common in men and women, but more common in current $(39.7 \%)$ and ex-smokers $(27 \cdot 7 \%)$ than in those who had never smoked $\left(12 \cdot 8 \% ; \chi^{2}=14 \cdot 1, \mathrm{p}=0.001\right)$.

In 22 subjects with chronic airways obstruction baseline $\mathrm{FEV}_{1}$ was $<60 \%$ predicted, and thus $\beta$ agonist reversibility was measured. Ten of these subjects $(45 \cdot 5 \%)$ had $\geqslant 160 \mathrm{ml}$ improvement in $\mathrm{FEV}_{1}$ following terbutaline. Of the remaining 43 subjects with chronic airways obstruction five were unable or unwilling to complete the methacholine challenge. Nonspecific bronchial responsiveness was increased in 23. Thus, overall 33 of $60(55.0 \%)$ subjects with chronic airways obstruction had either increased non-specific bronchial responsiveness or significant $\beta$ agonist reversibility. In 21 subjects attending twice, $\mathrm{PD}_{20}$ measurements were repeatable within two doubling doses of methacholine.

For the whole attender group multiple regression analysis with $\log \mathrm{PD}_{20}$ as the dependent

Table 3 Number (\%) of symptoms reported

\begin{tabular}{llll}
\hline & $\begin{array}{l}\text { Subjects with } \\
\text { chronic airways } \\
\text { obstruction } \\
(n=65)\end{array}$ & $\begin{array}{l}\text { Subjects without } \\
\text { chronic airways } \\
\text { obstruction } \\
(n=181)\end{array}$ & $\chi^{2}$ (p value) \\
\hline Cough (\%) & $33(50 \cdot 8)$ & $50(27 \cdot 6)$ & $10 \cdot 7(0 \cdot 001)$ \\
Sputum (\%) & $36(55 \cdot 4)$ & $53(29 \cdot 3)$ & $14 \cdot 4(<0 \cdot 001)$ \\
Wheeze (\%) & $39(60 \cdot 0)$ & $55(30 \cdot 4)$ & $17 \cdot 0(<0 \cdot 001)$ \\
Breathlessness (\%) & $19(29 \cdot 2)$ & $26(14 \cdot 4)$ & $7 \cdot 0(<0 \cdot 01)$ \\
One or more symptoms (\%) & $49(76 \cdot 6)$ & $88(50 \cdot 0)$ & $13 \cdot 5(<0 \cdot 001)$ \\
\hline
\end{tabular}

+ Breathless when walking on the level or at rest (equivalent to MRC grade $3+)^{9}$
Table 4 Proportion of subjects receiving inhaled $\beta$ agonists or steroids

\begin{tabular}{lll}
\hline & $\begin{array}{l}\text { Chronic airways } \\
\text { obstruction } \\
(n=65)\end{array}$ & $\begin{array}{l}\text { No chronic airways } \\
\text { obstruction } \\
(n=181)\end{array}$ \\
\hline No treatment & $41(63 \cdot 1 \%)$ & $169(93 \cdot 4 \%)$ \\
$\beta$ agonist only & $9(13 \cdot 8 \%)$ & $4(2 \cdot 2 \%)$ \\
Steroid $\pm \beta$ agonist & $14(21 \cdot 5 \%)$ & $8(4 \cdot 4 \%)$ \\
\hline
\end{tabular}

variable and age, sex, smoking habit, and baseline $\mathrm{FEV}_{1}$ (\% predicted) as independent variables showed a significant positive relationship between $\log \mathrm{PD}_{20}$ and baseline $\mathrm{FEV}_{1}(\mathrm{p}=$ $0.0001 ; R=0.3$ ), but no relationship between $\log \mathrm{PD}_{20}$ and the other independent variables.

\section{RESPIRATORY SYMPTOMS AND USE OF} BRONCHODILATORS

Subjects with chronic airways obstruction reported significantly more respiratory symptoms than those without, and wheeze was the commonest symptom (table 3); $76 \%$ of subjects with airways obstruction reported one or more symptoms. However, as symptoms were also common in those without chronic airways obstruction, the positive predictive value of symptoms for "obstructive" pulmonary function test results was low: only $35.8 \%$ of symptomatic subjects had chronic airways obstruction on pulmonary function testing. The symptom with the highest positive predictive value for airways obstruction was breathlessness (MRC grade $3+)^{9}: 19(42 \cdot 2 \%)$ of the 45 subjects reporting breathlessness had evidence of airways obstruction. Combinations of two or more symptoms were reported less frequently, but were more commonly associated with airways disease. For example, only 21 patients reported cough plus wheeze plus breathlessness, but 14 of them had airways obstruction (positive predictive value $66 \cdot 7 \%$ ).

Asthma or bronchitis was reported by $55.4 \%$ of subjects with airways obstruction and $23.7 \%$ of those with "normal" $\mathrm{FEV}_{1} / \mathrm{FVC}\left(\chi^{2}=21.9\right.$, $\mathrm{p}<0.001)$. The positive predictive value of reported asthma or bronchitis for evidence of chronic airways obstruction on pulmonary function testing was $45.6 \%$.

Twenty three $(35.4 \%)$ of the 65 subjects with chronic airways obstruction were using inhaled treatment (table 4), most commonly both inhaled steroids and $\beta$ agonists. Only two subjects were taking oral $\beta$ agonists and none theophylline. Age did not significantly affect the likelihood of treatment: eight of $27(20.6 \%)$ subjects of $<65$ years and 15 of $38(39.5 \%)$ of $\geqslant 65$ years were using treatment. Treated subjects had significantly worse baseline airways obstruction (mean (SE) $\mathrm{FEV}_{1} / \mathrm{FVC} \%=$ $48 \cdot 6(1.8) \%)$ than those on no treatment $(57.5$ $(0 \cdot 7) \% ; t=5 \cdot 3, \mathrm{p}<0.0001)$. Respiratory symptoms were reported by $70.0 \%$ of untreated subjects with chronic airways obstruction.

\section{Discussion}

Our data confirm the high prevalence of chronic airways obstruction in white adults in central 
Manchester. However, it is relevant to ask whether our study sample is representative. Many subjects initially selected had died or left the area. This problem has been described in other studies using information from GP lists and seems unavoidable. ${ }^{16}$ Nonetheless, the high response rate $(>90 \%)$ makes it likely that our figures are accurate. The preponderance of women in our population is expected in a sample containing many elderly people and agrees with OPCS estimates for central Manchester $(53 \%$ women in the population aged >45).${ }^{17}$ Our figures for current and ex-smoking were higher than recent OPCS estimates $(29 \%$ current smokers in a population aged $>50$ years).$^{18}$ It is probable that our results represent the situation in other urban white populations in Britain.

Unfortunately, only $31.5 \%$ of the eligible population attended for methacholine challenge. Although 113 subjects were excluded because of ischaemic heart disease or medications, most non-attenders were simply not prepared to undergo tests. This was particularly true of older subjects, and so attenders were younger than non-attenders. Similar problems have been reported in other studies of bronchial responsiveness. $^{21920}$ Nonetheless, attenders were representative of the study population in terms of sex distribution, smoking, diagnosed asthma/bronchitis, and reported respiratory symptoms.

Other studies of adults aged $\geqslant 65$ years have found a lower prevalence of airways obstruction. In a postal survey $8.4 \%$ reported asthma and $16.4 \%$ chronic bronchitis ${ }^{1}$; chronic airways obstruction has been found in $6.9 \%$ $\left(\mathrm{FEV}_{1} / \mathrm{FVC}<65 \%\right)^{21}$ and $15 \cdot 6 \%\left(\mathrm{FEV}_{1} / \mathrm{FVC}\right.$ $<60 \%$ ) in population studies. ${ }^{2}$ This variation may reflect differences in smoking habits or environmental influences between populations.

The proportion of subjects with diagnosed asthma or chronic bronchitis prescribed inhaled medications has been assessed in a study in the northern region of England using computerised GP records. ${ }^{22}$ In that study inhalers were prescribed for $6 \%$ of patients with chronic bronchitis and $66 \%$ of those with asthma (38\% of patients with a recorded diagnosis); prescribing rates were higher for patients aged 65-74. Our figures for prescribing in central Manchester are higher, perhaps because of differences in the population age range, data source, and diagnostic practices.

The problems of self-reported diagnoses as a measure of asthma prevalence have been discussed. ${ }^{23}$ The lack of agreed diagnostic criteria for asthma and chronic airways obstruction means that physicians vary in their diagnostic labelling and may be influenced by non-clinical parameters such as age and sex. ${ }^{24}$ As a result, patients may acquire multiple diagnoses ${ }^{25}$; this is demonstrated by the number of subjects in our population reporting both asthma and bronchitis. Some studies have found evidence of overreporting of unconfirmed diagnoses ${ }^{326}$; others have suggested underreporting, particularly by older men with chronic bronchitis. ${ }^{27}$
We have objectively assessed the prevalence of chronic airways obstruction by spirometric testing in a representative sample. Since $\mathrm{FEV}_{1} /$ FVC\% decreases with age, we calculated predicted levels and lower limits of normal for subjects aged $\geqslant 65$ years. ${ }^{15}$ To avoid overestimation of airways reversibility in patients with low baseline $\mathrm{FEV}_{1}$ we defined reversibility as a fixed volume increase in $\mathrm{FEV}_{1}$, rather than a percentage increase over baseline. ${ }^{13}$ Measurement of bronchial responsiveness by the Newcastle dosimeter method usually includes six measurements of $\mathrm{FEV}_{1}$ after each methacholine dose. ${ }^{11}$ To avoid fatigue in our elderly population this was reduced to three; this adapted method has been shown to be reproducible in older adults. ${ }^{10}$ As is customary for this method of bronchial challenge, $\mathrm{PD}_{20}$ was calculated using the mean rather than the maximum of the three $\mathrm{FEV}_{1}$ recordings $^{1011}$; we confirmed that this gave better repeatability.

The prevalence of reported asthma or bronchitis was similar to that of measured chronic airways obstruction. However, both reported diagnoses and symptoms were poor predictors of chronic airways obstruction. This has implications for other epidemiological studies of asthma or chronic airways obstruction, some of which have relied solely on self-reporting of diagnoses and symptoms. ${ }^{2829}$

Only one third of subjects with airways obstruction were using inhaled medications. This may reflect tolerance of respiratory symptoms by elderly people or therapeutic nihilism on behalf of their doctors. The lack of patients taking theophylline is surprising; this may reflect either poor patient compliance or local prescribing habits. The need for serum monitoring and the incidence of side effects has decreased the popularity of theophylline. ${ }^{30}$

Over half of our subjects with chronic airways obstruction had bronchodilator reversibility or increased bronchial responsiveness. The latter has been shown to predict spirometric improvement on treatment in elderly asthmatic subjects. ${ }^{10}$ A single measurement of bronchodilator reversibility is less reliable as a predictor of response to treatment. ${ }^{31}$ The significance of increased bronchial responsiveness in patients with chronic airways obstruction is also unclear; a strong correlation between baseline $\mathrm{FEV}_{1}$ and $\mathrm{PD}_{20}$ in these patients has led to the suggestion that increased bronchial responsiveness is merely the result of reduced airway calibre rather than an indication of airways lability. ${ }^{32}{ }^{33}$ We have confirmed the relationship between baseline $\mathrm{FEV}_{1}$ and $\mathrm{PD}_{20}$, but the low coefficient of multiple regression suggests that the high prevalence of increased bronchial responsiveness in our subjects is not merely the result of low $\mathrm{FEV}_{1}$.

In summary, we have found high levels of untreated chronic respiratory morbidity in the adult white population of central Manchester, but no evidence of age bias in the proportion of patients receiving treatment. Adults with respiratory symptoms should have pulmonary function formally assessed; those with airways obstruction may benefit from bronchodilator treatment. 
The authors wish to thank the British Geriatrics Society and Central Manchester Healthcare Trust for funding this project, the Institute of Clinical Physiology at Manchester Royal Infirmary for the loan of equipment, and Acorn Nebulisers Lt for supplying nebulisers. We are also indebted to the following general practitioners for allowing us to study their patients: D g B r practioners for allowing us to study their patients: D Hutton, Dr H MacDonald, Dr L Reynolds, and Dr I Sethi.

1 Horsley J R, Sterling I J, Waters W E, Howell J B. Respiratory symptoms among elderly people in the New Forest are as assessed by postal questionnaire. Age Ageing 1991;20: 325-31.

2 Dow L, Coggon D, Holgate S T. Respiratory symptoms as predictors of airways lability in an elderly population. Respir Med 1992;86:27-32.

3 Lundback B, Nystrom L, Rosenhall L, Stjernberg N. Obstructive lung disease in northern Sweden: respiratory structive lung disease in northern Sweden: respiratory
symptoms assessed in a postal survey. Eur Respir 71991 ; 4:257-62.

4 Viegi G, Paoletti P, Carrozzi L, Vellutini M, Diviggiano E, Di Pede C, et al. Prevalence rates of respiratory symptoms in Italian general population samples exposed to differen levels of air pollution. Environ Health Perspect 1991;94 95-9.

5 Banerjee D K, Lee G S, Malik S K, Daly S. Underdiagnosi of asthma in the elderly. $B r \mathcal{F}$ Dis Chest $1987 ; 81: 23-9$.

6 Hatton P. "Primum non nocere" - an analysis of drugs prescribed to elderly patients in private nursing homes registered with Harrogate Health Authority. Care of the Elderly 1990;2:166-9.

7 Nolan L, O'Malley K. The need for a more rational approach to drug prescribing for elderly people in nursing homes. Age Ageing 1989;18:52-6.

8 Sherman C B, Tollerud D J, Heffner L J, Speizer F E, Weis $\mathrm{S} \mathrm{T}$. Airway responsiveness in young black and white women. Am Rev Respir Dis 1993;148:98-102.

9 van den Lende R, Orie N G M. The MRC-ECCS questionnaire on respiratory symptoms (use in epidemiology) Scand F Respir Dis 1972;53:218-26.

10 Connolly M J, Kelly C, Walters E H, Hendrick D J. An assessment of methacholine inhalation tests in elderly asthmatics. Age Ageing 1988;17:123-8.

11 Hendrick D J, Fabbri L M, Hughes J M, Banks D E, Barkman $\mathrm{H}$ W, Connolly M J, et al. Modification of the methacholine inhalation test and its epidemiological use in polyurethane workers. Am Rev Respir Dis 1986;133: in polyur.

12 Cotes J E. Lung function. Oxford: Blackwell Scientific Pubications, 1968 .

13 Tweeddale P M, Alexander F, McHardy G J R. Short term variability in $\mathrm{FEV}_{1}$ and bronchodilator responsiveness in patients with obstructive ventilatory defects. Thorax 1987 42:487-90.

14 Connolly M J, Avery A J, Walters E H, Hendrick D J. The relationship between non-specific bronchial responsiveness to methacholine and histamine in asthmatic subjects. Pulm Pharmacol 1988;1:53-8.

15 Enright P L, Kronmal R A, Higgins M, Schenker $M$ Haponik E F. Spirometry reference values for women and men 65 to 85 years of age. Cardiovascular Health Study. Am Rev Respir Dis 1993;147:125-33.

16 Milne J S, Maule M M, Williamson J. Method of sampling in a study of older people with a comparison of respondents and non-respondents. Brf Prev Soc Med 1971;25:37-41.

17 OPCS. Key population and vital statistics 1991 . Series VS no. 18, PP1 no 14 . London: HMSO.

18 OPCS. General household survey 1992. Series GHS no. 23. London: HMSO.

19 Trigg C J, Bennett J B, Tooley M, Sibbald B, D'Souza M F D, Davies R J. A general practice based survey of bronchial hyperresponsiveness and its relation to symptoms, age, sex, atopy, and smoking. Thorax 1990;45 866-72

20 Mortagy A K, Howell J B L, Waters W E. Respiratory symptoms and bronchial reactivity: identification of a syndrome and its relation to asthma. $B M \mathcal{F} 1986 ; 293$ 525-9.

21 Isoaho R, Puolijoki H, Huhti E, Kivela S-L, Laippala P, Tala E. Prevalence of chronic obstructive pulmonary disease in elderly Finns. Respir Med 1994;88:571-80.

22 Roberts S J, Bateman D M. Which patients are prescribed inhaled anti-asthma drugs? Thorax 1994;49:1090-5.

23 Samet J M. International workshop on the etiology of asthma. Epidemiologic approaches for the identification of asthma. Chest 1987;91(Suppl):74-8.

24 Dodge R B, Burrows B. The prevalence of and incidence of asthma and asthma-like symptoms in a general population asthma and asthma-like symptoms in a gener.

25 Dodge R, Cline M G, Burrows B. Comparisons of asthma emphysema, and chronic bronchitis diagnoses in a general population sample. Am Rev Respir Dis 1986;133:981-6.

26 Viegi G, Baldacci S, Vellutini M, Carrozzi L, Modena P, Pedreschi $M$, et al. Prevalence rates of diagnosis of asthma in general population samples of Northern and Central Italy. Monaldi Arch Chest Dis 1994;49:191-6.

27 McWhorter W P, Polis M A, Kaslow R A. Occurrence, predictors, and consequences of adult asthma in NHANESI and follow-up survey. Am Rev Respir Dis 1989 139:721-4.

28 Menezes A M B, Victora C J, Rigatto M. Prevalence and risk factors for chronic bronchitis in Pelotas, RS, Brazil: a population-based study. Thorax 1994;49:1217-21.

29 Samet J M, Schrag S D, Howard C A, Key C R, Pathak D R. Respiratory disease in New Mexico population sample R. Respiratory disease in New Mexico population sample
of Hispanic and non-Hispanic whites. Am Rev Respir Dis of Hispanic and

30 Lam A, Newhouse M T. Management of asthma and chronic airflow limitation. Are methylxanthines obsolete? Chest 1990;98:44-52.

31 Ramsdale E H, Hargreave F E. Differences in airway responsiveness in asthma and chronic airflow obstruction. Med Clin North Am 1990;74:741-51.

32 Postma D S, de Vries K, Koeter G H, Sluiter H J. Independent influence of reversibility of airflow obstruction and nonspecific hyperreactivity on the long-term course of lung function in chronic airflow obstruction. $A m$ Rev Respir Dis 1986;134:276-80.

33 Kesten S, Rebuck A S. Is the short-term response to inhaled beta-adrenergic agonist sensitive or specific for distinguishing between asthma and COPD? Chest 1994:105: 1042-5. 